\title{
Estrategias audiovisuales, educomunicativas y recreativas para la transformación social y la creación de vínculos comunitarios ${ }^{*}$ Obras expresivas audiovisuales comunitarias
}

\author{
Victoria E. Valencia-Calero** \\ Juan Camilo Hernández Ortiz*** \\ Recibido: 2020-02-16 • Enviado a pares: 2020-03-10 \\ Aprobado por pares: 2020-04-21 • Aceptado: 2020-05-22 \\ https://doi.org/10.22395/angr.v19n37a9
}

\section{Resumen}

Este artículo retoma el concepto de obras expresivas audiovisuales comunitarias y su estrecho vínculo con la recreación. Este estudio parte de algunos resultados del proyecto de investigación. El objetivo es visibilizar la importancia de desarrollar procesos educomunicativos de mediano y largo aliento en los que no solo se vinculen lenguajes audiovisuales, sino también otras formas de expresión lúdico-creativas. El enfoque metodológico del proyecto de investigación fue cualitativo, basado en la observación profunda y la descripción densa de la etnografía clásica, así como en la etnografía audiovisual y en la etnografía virtual. Los principales hallazgos, desde la perspectiva de la comunicación basada en las mediaciones, es que las OEAC tienen lugar en el centro mismo de las comunidades, en los usos, las relaciones y los vínculos que se construyen en los procesos de comunicación. Además de funcionar socialmente como mediaciones en el sentido desarrollado por Martín-Barbero (1991), están conformadas por mediaciones semióticas o lenguajes lúdico-creativos (Mesa, 2004). En conclusión, se considera que las OEAC abren posibilidades de transformación social porque desarrollan procesos que trascienden las películas, reconocen los aspectos sociohistóricos, fortalecen la identidad colectiva y hacen posible una fluida relación entre sujetos y contextos.

Palabras clave: comunicación; educación; proceso de comunicación; comunicación cultural; educación cultural; acción sociocultural; medios de comunicación; medios de información; artes visuales.

Artículo basado en el proyecto de investigación Elementos de educación popular y recreación presentes en trabajos audiovisuales realizados por organizaciones o comunidades como parte de procesos de movilización, participación y creación o fortalecimiento de vínculos sociales, Grupo de Investigación en Educación Popular, Universidad del Valle, Colombia.

" Doctoranda en Historia y Artes, Universidad de Granada, Granada, España. Profesora asistente, integrante del Grupo de Investigación en Educación Popular, Universidad del Valle, Cali, Colombia. Correo electrónico: victoria.valencia@correounivalle.edu.co. Orcid: https://orcid.org/0000-0001-6658-4035

*** Estudiante Programa Académico de Recreación, Universidad del Valle, Cali, Colombia. Con experiencia en procesos educativos y comunitarios desde la recreación y las expresiones artísticas. Correo electrónico: juan. hernandez.ortiz@correounivalle.edu.co. Orcid: https://orcid.org/0000-0003-2184-829X 


\title{
Audiovisual, Educommunicational and Recreational Strategies for Social Transformation and Creation of Communitary Bonds
}

\begin{abstract}
This article retakes the concept of community expressive audiovisual works (CEAW) and its close relation with recreation. This study is based on some results of a research project. Its goal is to make evident the importance of developing educommunicational processes in the short and mid-term in which not only audiovisual languages are involved, but also other types of ludic and creative forms of expression. The project had a qualitative research method based on deep observation and dense description of classical ethnography, as well as audiovisual and virtual ethnography. The main findings, from the perspective of communication-based on mediations, is that the CEAW have their place in the center of communities, in the uses, the relations, and the bonds that are created within the communication processes. Besides working as social mediations in the sense proposed by Martín-Barbero (1991), they are shaped by semiotic mediations or ludic and creative languages (Mesa, 2004). In conclusion, it is considered that the CEAW create social transformation possibilities because they develop processes that transcend movies, recognize the social and historical aspects, strengthen the collective identity and make possible a fluid relation between subjects and contexts.
\end{abstract}

Keywords: communication; education; communication processes; cultural communication; cultural education; social and cultural action; communication media; information media; visual arts.

\section{Estratégias audiovisuais, educomunicacionais e recreativas para a transformação social e a criação de vínculos comunitários}

\section{Obras expressivas audiovisuais comunitárias}

\begin{abstract}
Resumo
Este artigo retoma o conceito de obras expressivas audiovisuais comunitárias e seu estreito vínculo com a recreação. Este estudo parte de alguns resultados de um projeto de pesquisa. $\mathrm{O}$ objetivo é visibilizar a importância de desenvolver processos educomunicacionais de médio e longo prazo aos quais não somente são vinculadas linguagens audiovisuais, mas também outras formas de expressão lúdico-criativas. A abordagem metodológica do projeto de pesquisa foi qualitativa, baseada na observação profunda e na descrição densa da etnográfica clássica, bem como na etnografia audiovisual e na virtual. Os principais achados, sob a perspectiva da comunicação baseada nas mediações, é que as OEAC têm lugar no centro das comunidades em si, nos usos, nas relações e nos vínculos que são construídos nos processos de comunicação. Além de funcionar socialmente como mediações no sentido desenvolvido por MartínBarbero (1991), estão conformadas por mediações semióticas ou linguagens lúdico-criativas (Mesa, 2004). Em conclusão, é considerada que as OEAC abrem possibilidades de transformação social porque desenvolvem processos que ultrapassam os filmes, reconhecem os aspectos sócio-históricos, fortalecem a identidade coletiva e tornam possível uma fluida relação entre sujeitos e contextos.

Palavras-chave: comunicação; educação; processo de comunicação; comunicação cultural; educação cultural; ação sociocultural; meios de comunicação; meios de informação; artes visuais.
\end{abstract}




\section{Introducción}

En Colombia, como en los otros países de América Latina, las comunidades, las organizaciones sociales, los grupos minoritarios y los colectivos culturales han hallado en la comunicación audiovisual una de sus principales estrategias para visibilizarse, promover y dar forma a la movilización social; activar la memoria viva de los pueblos; crear vínculos hacia adentro y hacia afuera, y formar sujetos empoderados tanto de sus territorios como de sus propias historias individuales y colectivas. Pero no se trata solo de hacer películas, sino de desarrollar procesos interdisciplinarios de largo aliento, con un profundo sentido educativo, que se nutran de las diversas formas expresivas y creativas. Este artículo presenta una mirada de estos procesos, no solo como audiovisuales realizados con acompañamiento comunitario, sino como obras expresivas audiovisuales comunitarias —OEAC— (Gómez, González y Valencia-Calero, 2020), dinamizadas por elementos educativos y lúdico-creativos.

En primer lugar, se expone qué son las OEAC (Gómez, González y Valencia-Calero, 2020) a partir de algunos resultados de la investigación Elementos de educación popular y recreación presentes en trabajos audiovisuales realizados por organizaciones o comunidades como parte de procesos de movilización, participación y creación o fortalecimiento de vínculos sociales (Gómez, González y Valencia-Calero, 2016). En este sentido, se muestran los principales referentes conceptuales de las OEAC y se exploran sus posibilidades desde la recreación enfocada en tres dimensiones: la actividad social general, la recreación pedagógica y la actividad interna (Mesa, 2004). En segundo lugar, se explicita la metodología del estudio. Por último, se presentan algunos hallazgos y conclusiones.

\section{Obras expresivas audiovisuales comunitarias (OEAC)}

Durante la investigación se revisaron dieciocho procesos comunitarios de comunicación audiovisual: Asociación Colectiva de Medios Alternativos de Jóvenes del Distrito de Aguablanca (Mejoda) con el Festival de Cine y Video Comunitario del Distrito de Aguablanca, Fesda (Cali); Tikal Producciones (Cali); Cine pa'l Barrio de la Fundación Nacederos (Cali); Tejido de Comunicaciones de la Asociación de Cabildos Indígenas del Norte del Cauca (ACIN), Çxhab Wala Kiwe; Productora Independiente Nasa Luuçx Comunicaciones (Norte del Cauca); Centro de Comunicación Indígena de la Sierra Nevada de Santa Marta, Zhigoneshi; Realizaciones Yosokwi, Sierra Nevada de Santa Marta; Festival Internacional Cine en la Isla, Fecisla (Isla Fuerte, Bolívar); Colectivo de Comunicaciones Kuchá Suto (San Basilio de Palenque, Bolívar) (figural); Colectivo de Comunicación de Narradores y Narradoras de la Memoria Línea 21 (Montes de María); Ojo al Sancocho con el Festival Internacional de Cine y Video Alternativo y Comunitario (Bogotá); Corporación Afrocolombiana de Desarrollo Social y Cultural (Carabantú) con el Festival Internacional de Cine Comunitario Afro Kunta Kinte (Medellín); Escuela 
Audiovisual Infantil de Belén de los Andaquíes (Caquetá); la experiencia del realizador independiente Víctor Alfonso González Urrutia en Villa Paz (Villapaz', Jamundí, Valle del Cauca); Grupo de Guapi (Cali); Ángeles de la Calle (El Pozón, Cartagena, Bolívar); la muestra de cine y video indígena de Colombia, Daupará; la Escuela de Creación Documental y los semilleros creativos del área de comunicaciones de la Asociación Campesina de Antioquia (ACA).

Del análisis de los procesos de estas experiencias, en particular de la muestra de cine y video indígena Daupará y de la Escuela de Creación Documental de la ACA, surgió el concepto de Obras expresivas audiovisuales comunitarias - OEAC - , que no se refiere solo producciones audiovisuales, sino a una amplia variedad de obras, todas ellas ancladas a un proyecto político de transformación social. Por ello, se habla de OEAC como una manera de dar cuenta de los diversos proyectos expresivos que conjugan múltiples remisiones a prácticas culturales locales con otras tomadas de la cultura transnacional y que, además, apelan a narrativas y formatos múltiples y diversos (Gómez, González y Valencia-Calero, 2020, pp. 171-172).

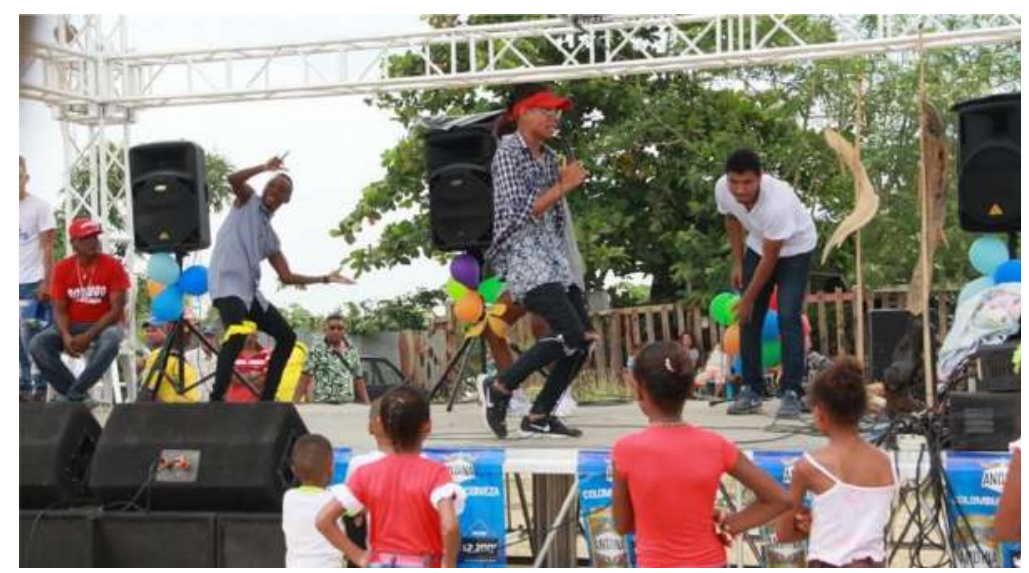

Figura 1. San Basilio de Palenque, Departamento de Bolívar

Fuente: Colectivo de Comunicaciones Kuchá Suto (2019).

Las OEAC no son obras aisladas ni con un valor únicamente en sí mismas. Lo que importa es el contexto que les da origen, la organización de las comunidades que las sustentan, la transformación de los sujetos que participan y los procesos de enseñanza-aprendizaje. Los realizadores, en su mayoría (aunque no exclusivamente), son endógenos y se enfocan en las características e intereses de cada territorio. Lo fundamental de estas obras es que los productos audiovisuales están inmersos en procesos sociales.

Aunque el corregimiento oficialmente se llama Villa Paz (dos palabras separadas), en este artículo se usa Villapaz (una sola palabra) respetando la manera en que lo escribe la comunidad villapaceña. 
Para Aguilera y Polanco (2011), la característica esencial del video comunitario es que las organizaciones que lo aprovechan "conciben su acción como parte de una lucha y como forma de enfrentar a los que entienden, en algunas circunstancias, son sus adversarios" (p. 24). En Colombia los adversarios pueden ser diversos: el Estado mismo, sus agentes y proyectos desconectados del bienestar de los territorios; los grupos armados ilegales; variadas formas de violencia; los fines netamente comerciales de algunas empresas y gremios privados que, a partir de figuras legales, se apropian de lo público, despojan y afectan el medioambiente; el olvido de la historia colectiva y de la propia historia; la invisibilización o alteración de la imagen del otro o de la propia, etc.

Los sujetos que lideran las OEAC actúan como agentes transformadores (líderes comunitarios o gestores socioculturales) que trabajan desde la cultura y los saberes propios para potenciar las expresiones lúdicas y creativas de cada comunidad (figura 2). Restrepo y Valencia (2016) señalan que, en el caso de las comunidades indígenas, han sido muy importantes los procesos de las producciones porque ha habido interacción intercultural en las diferentes etapas de cada proyecto: en la preproducción, la producción y la circulación. Como ganancia, se han gestado nuevos conocimientos, además de aprender las dinámicas de la realización fílmica (Restrepo y Valencia, 2016). Por su parte, Goyeneche-Gómez (2012) afirma que "las películas permiten analizar la propia conciencia de la historia que se evidencia en las representaciones de los hechos históricos, y la forma como se construye y asume ideológicamente el pasado" (p. 392).

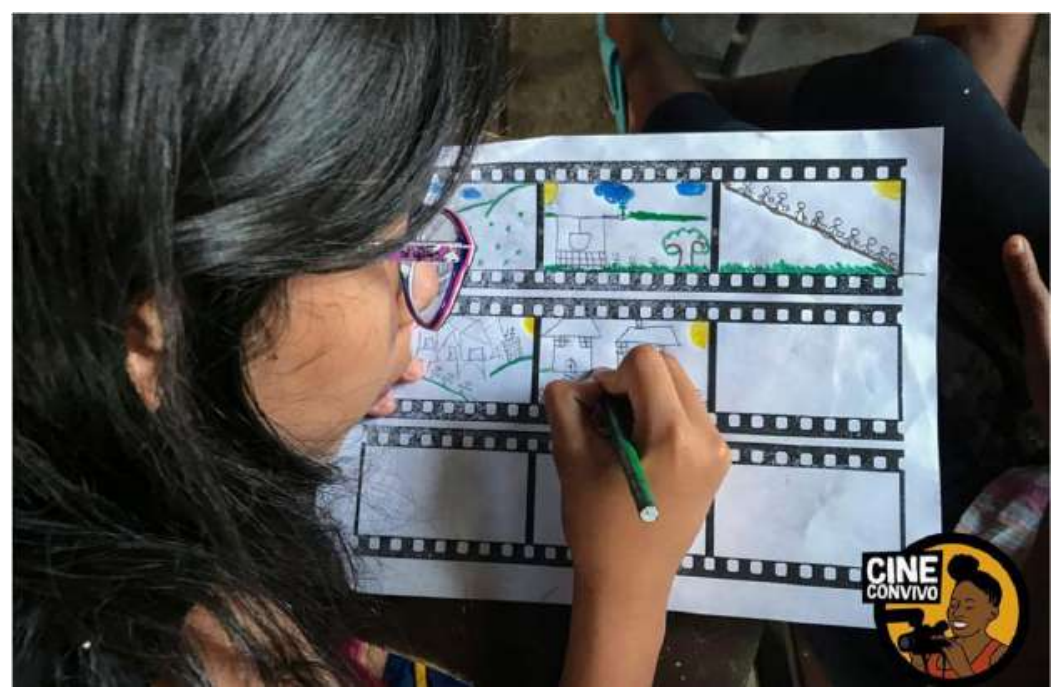

Figura 2. Proceso creativo de Cine Convivo que reflexionó sobre las mediaciones audiovisuales en contextos comunitarios

Fuente: Eduardo Montenegro (2019). 
Las obras expresivas audiovisuales comunitarias comparten características de la educación popular y de la investigación-acción participativa —IAP_ por la importancia que se da a los procesos, al diálogo intercultural e intracultural, a los sujetos y a las comunidades. Las OEAC comparten con la educación popular la idea de que solo cuando un sujeto "alcance a comprender, a sentir y a conocer su mundo particular, a través de una experiencia práctica de transformación colectiva del mismo, su pensamiento y su expresión ganarán un significado más allá de aquel mundo que lo dominaba" (Freire, 1975). A través de las manifestaciones expresivas, de alguna manera, se ejerce el derecho a soñar y a diseñar mundos diferentes, más esperanzadores, con vínculos sociales fuertes que posibiliten la formación de "sujetos políticos, transformadores del mundo y no adaptables a él" (Freire, s.f., p. 117). En las OEAC, las comunidades son dueñas de sus propias imágenes audiovisuales, observan sus realidades, trayectos históricos, condiciones sociales y formas de vida, asumiendo un papel transformador de sus propios mundos.

Las OEAC tienen en común con la investigación-acción participativa, que son procesos abiertos, anclados en la vida cotidiana de los pueblos y enriquecidos por sus propios saberes y por saberes que vienen de afuera. Además, ambos buscan "la transformación estructural de la sociedad y de la cultura como objetivos sucesivos y parcialmente coincidentes" (Anisur y Fals, 2013, p. 257). En este sentido, requieren de la participación y del compromiso de los sujetos. Para Fals Borda (2013), con la IAP se comienzan a compartir valores, actitudes y se genera una filosofía de vida, que es el corazón de este enfoque de investigación e intervención social. Más allá de los productos comunicativos — su calidad o su éxito—, lo que importa en la obras expresivas audiovisuales comunitarias es lo que se pone en juego en la realización, la edición y la puesta en relación con la comunidad: vínculos, interacciones, sentidos, creencias, ideologías, modelos de sociedad, compromiso con el otro, etc. Los participantes son parte integral de las comunidades. Por ello, se exploran y analizan las diferentes realidades sociohistóricas de cada contexto; se procura la sensibilización de las personas con respecto a determinadas situaciones; se visibilizan sus problemáticas e inquietudes, y se dinamiza la formación de organizaciones y grupos interesados en la transformación de sus territorios.

El sentido político de las OEAC no viene dado solo por sus contenidos, discursos, características estéticas o por la participación comunitaria, sino también por la intención de los sujetos y de las comunidades de procurarse el acceso a las tecnologías de punta. En este sentido, es manifiesta su voluntad de aprender (figura 3) —en muchas ocasiones de manera autodidácta y empírica - a manejar cámaras de video (de smartphone, réflex, semiprofesionales y hasta profesionales, si logran conseguirlas) para perfeccionarse, en la práctica, como camarógrafos y sonidistas. Al aprovechar los recursos de grabación de los teléfonos celulares, al buscar software de edición gra- 
tuitos y tutoriales en internet para aprender a editar o a abrir canales de proyección, los sujetos pasan de la pasividad a la acción, dejan de ser espectadores para ser productores de sus propios discursos audiovisuales (Gómez, González y Valencia-Calero, 2020). Este empoderamiento político se da como resultado de procesos de educación no formal. En este sentido, afirma Espinosa (2012):

La formación en este nivel es difusa, compleja, difícil de moldear; es por ello que los roles se confunden y, en el proceso en que el formador forma, va delegando su rol a los mismos formandos, quienes poco a poco irán formándose a sí mismos e irán formando a los demás, transformándose en la medida que asumen y experimentan una educación liberadora. (p. 73)

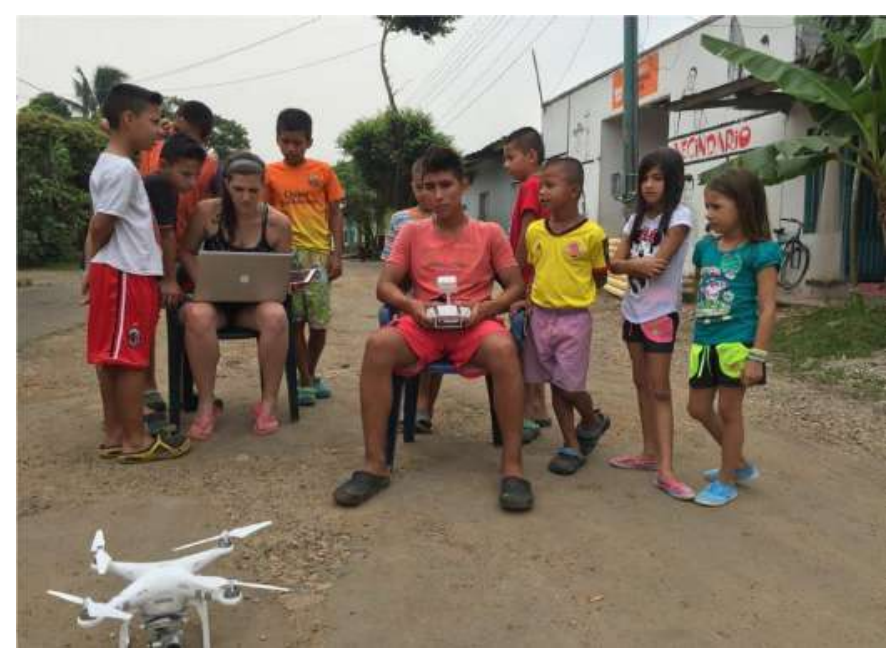

Figura 3. Proceso de aprendizaje con nuevos repertorios tecnológicos audiovisuales en la Escuela Audiovisual Infantil de Belén de los Andaquíes

Fuente: Escuela Audiovisual Infantil (2016).

Con respecto a los jóvenes, De Oliveira (2008) destaca que las nuevas generaciones tienen claros la posibilidad y el derecho a acceder a las tecnologías, expresarse audiovisualmente, dar rienda suelta a su creatividad y producir sus propios mensajes. En este sentido, afirma: "Los jóvenes quieren ir más allá de la educación para mirar los medios y conquistar el «derecho a la pantalla»" (De Oliveira, 2008, p. 87). Sin embargo, en sociedades como la colombiana se hace necesario considerar la complejidad de la relación entre la comunicación, los medios y el progreso social. Aunque hay más posibilidades de acceso a las tecnologías y a los espacios de visibilización, no todos los colectivos y sujetos tienen las mismas oportunidades de adquirir tecnologías de punta, pagar servicios eficientes de internet y alcanzar espacios óptimos de proyección para sus obras; este es un tema que se debe seguir trabajando para intentar equilibrar estas desigualdades (Couldry et al, 2018). 
En algunas OEAC hay puestas en escena y actuaciones que permiten recordar el teatro del oprimido (Boal, 2006). Hay interpretaciones de ficción dentro de la realidad y realidad en la ficción. Este juego, a veces imperceptible, posibilita momentos de reflexión y la aparición de soluciones a problemas de las comunidades. Esto ocurre, por ejemplo, en las obras de Víctor Alfonso González Urrutia (Gufilms²), artesano audiovisual independiente que cuenta con el apoyo de su comunidad Villapaz. En este caso, sus familiares, amigos y vecinos aportan información para las historias y actúan en los filmes, lo que establece vínculos y conversaciones en torno a las temáticas y dinámicas de cada creación (figura 4). Verse en pantalla posibilita cierta distancia, un nivel de análisis diferente que puede desencadenar en decisiones o actitudes colectivas frente a las realidades que se reflejan en las ficciones interpretadas por ellos mismos. González Urrutia ha tematizado, por ejemplo, la desobediencia infantil y juvenil, recreando con imágenes audiovisuales algunas de sus consecuencias. Esto, al ser visto por los niños de Villapaz, ha posibilitado espacios de diálogo en torno a los riesgos que se pueden correr si desobedecen las órdenes o se rechazan los consejos de las personas mayores. En este sentido, Gumucio-Dragon (2011) plantea que "la participación de los actores involucrados es esencial en las propuestas de comunicación para el desarrollo, alternativa y participativa, que son las expresiones más reconocidas de la comunicación para el cambio social" (p. 28). Por su parte, Huergo (2008) agrega que lo que los sujetos participantes observan en la pantalla se convierte en una interpelación "que a su vez se presenta como conjunto textual, articulada con identificaciones o reconocimientos subjetivos. Esta zona de articulación posee, en cuanto tal, una dimensión innegablemente formativa" (p. 74).

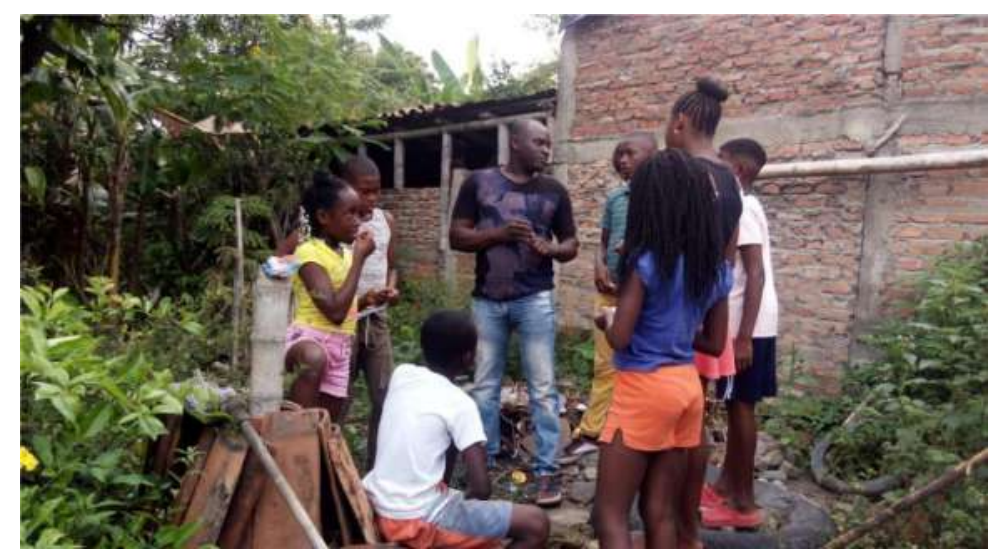

Figura 4. Víctor Alfonso González Urrutia explica a sus actores (niños y niñas de Villapaz) el sentido de la obra expresiva audiovisual La Pucha, realizado con su primer grupo del Semillero Gufilms.

Fuente: González Urrutia, archivo personal, 2016.

\footnotetext{
2 Víctor Alfonso González Urrutia marca sus obras con el sello Producciones Gufilms: González Urrutia Films, porque desde sus inicios ha tenido la colaboración de su familia.
} 
El componente educomunicativo de las obras expresivas audiovisuales comunitarias pasa por el reconocimiento de las propias matrices culturales y de las otras culturas. En este sentido, pasa por la formación perceptiva, sensitiva, interpretativa, social, relacional y por lo que Acaso y Ávila (2011) describen como educación artística o arteducación, que es el desplazamiento de las artes (en este caso audiovisuales) hasta la educación como una manera de poner en relación lo cognitivo y lo emocional en los sujetos. La conjugación de la comunicación, el arte y la creatividad es una estrategia para la transformación de los ambientes sociales.

La educomunicación, que tiene su énfasis en el diálogo y que se presenta como "una relación interpelante entre saberes diferentes y desigualmente constituidos" (Hleap, 2013, p. 189), no niega las diferencias y las desigualdades, sino que las reconoce como una manera de enriquecer los procesos de comunicación y educación:

De manera que las diferencias (constituidas a través de historias de lucha material y simbólica y constitutivas de nuestra identidad) se «encuentran» y se «reconocen» en el diálogo (y no siempre de manera armoniosa y feliz); y al reconocerse y encontrarse se refiguran. (Huergo, 2015, pp. 16-17)

Las OEAC, durante todos los momentos de los procesos, posibilitan el aprendizaje, la construcción individual y colectiva de conocimientos, la interacción entre sujetos y las interpelaciones entre estos. En tanto educomunicación hay movimiento, flexibilidad, intercambio de significados, transformación de sentidos,

construcción-deconstrucción-reconstrucción permanente de la realidad. Es, en suma, una forma de pedagogía crítica que concibe los procesos educativos, la comunicación, los medios y las tecnologías como herramientas de análisis y de acción para la comprensión y la transformación del mundo. (Barbas-Coslado, 2012, p. 167)

Su sentido ético y político hace de esta apuesta educativa una propuesta de educación popular. Según Narváez-Montoya (2019), la educomunicación concibe los medios audiovisuales como estrategias óptimas para la educación, dada su facilidad de lectura y

su capacidad de expansión social y geográfica; pero, sobre todo, son una forma de oponerse a los medios dominantes, es decir, oficiales y privados, los cuales serían, por naturaleza, alienantes en cuanto promueven fundamentalmente el consumismo, e ideológicamente reaccionarios en cuanto defensores del statu quo. (p. 10)

En definitiva, las OEAC son procesos educomunicativos porque se juegan en el campo de la cultura, las representaciones sociales, la negociación de sentidos y significados, los vínculos entre sujetos, las transformaciones sociales; y todo esto ocurre en el corazón mismo de las comunidades. Las tecnologías no determinan los 
procesos, por el contrario, son los sujetos los que definen el uso que se hace de los repertorios tecnológicos.

\section{El componente recreativo de las OEAC}

Además de lo que ya se ha mencionado, las obras expresivas audiovisuales comunitarias se caracterizan por tener componentes recreativos consecuentes, desde el enfoque de la educación popular, con la educomunicación. En primer lugar, tanto las prácticas educomunicativas como las recreativas tienen objetivos comunes: crear o fortalecer vínculos sociales y resignificar vivencias a través de diferentes manifestaciones expresivas (creativas, artísticas, lúdicas, tecnomediadas, etc.).

En segundo lugar, en las OEAC es posible identificar las tres dimensiones de la recreación señaladas por Mesa (2004): i) la actividad social general, la cual corresponde tanto al legado de las tradiciones como a las más recientes creaciones tecnológicas que, desde lo sociocultural, actúan en el plano de lo simbólico; ii) la recreación "dirigida" o pedagógica, que tiene como base la intencionalidad de enseñar, comunicar las tradiciones recreativas, propiciar el desarrollo de la imaginación creadora y transformadora de las mismas para influir en cambios internos y externos de los sujetos; iii) la actividad interna, que define los lenguajes lúdico-creativos ${ }^{3}$ de origen sociocultural y que intervienen en la actividad interna (intrapsicológica), por su carácter de herramienta semiótica o de lenguaje.

Es posible encontrar estas dimensiones de la recreación en las OEAC. Los documentales de la Escuela de Creación Documental de la Asociación Campesina de Antioquia (ACA) dan cuenta, por ejemplo, de las tradiciones y aspectos de carácter sociohistórico y cultural que se convierten en estrategias narrativas de las vivencias de quienes participan de las obras (figura 5). Se trata de procesos comunicativos en los que se reconocen e incluyen sus tradiciones, interacciones y narraciones. Durante la planeación y desarrollo de las obras emergen características que hacen del diseño y la preparación un ejercicio de recreación "dirigida" o pedagógica. La primera dimensión se identifica en el carácter creativo que surge a partir de las situaciones cotidianas, las vivencias de los participantes y sus tradiciones arraigadas. La segunda tiene que ver con quienes lideran los procesos comunicativos y cumplen el rol de agentes educativos, "cuya acción profesional o voluntaria se caracteriza por la intervención sobre el medio a nivel de las relaciones entre individuos y las obras culturales, y eventualmente a nivel de las estructuras" (Besnard, 1988, pp. 71-72).

Los lenguajes lúdico-creativos son, en esencia, la expresión gráfico-plástica, la expresión lúdico musical, la danza, los juegos dramáticos y el teatro, entre otras expresiones que tienen relación con las artes sin considerarse estrictamente arte. Una de las principales diferencias entre el arte y la recreación consiste en que esta última tiene un carácter de exploración y voluntariedad para realizar la actividad artística que, además, hace parte de un proceso social, organizativo y pedagógico. En cambio, en el arte priman la obra, el artista y la disciplina que conlleva a la obligatoriedad. 


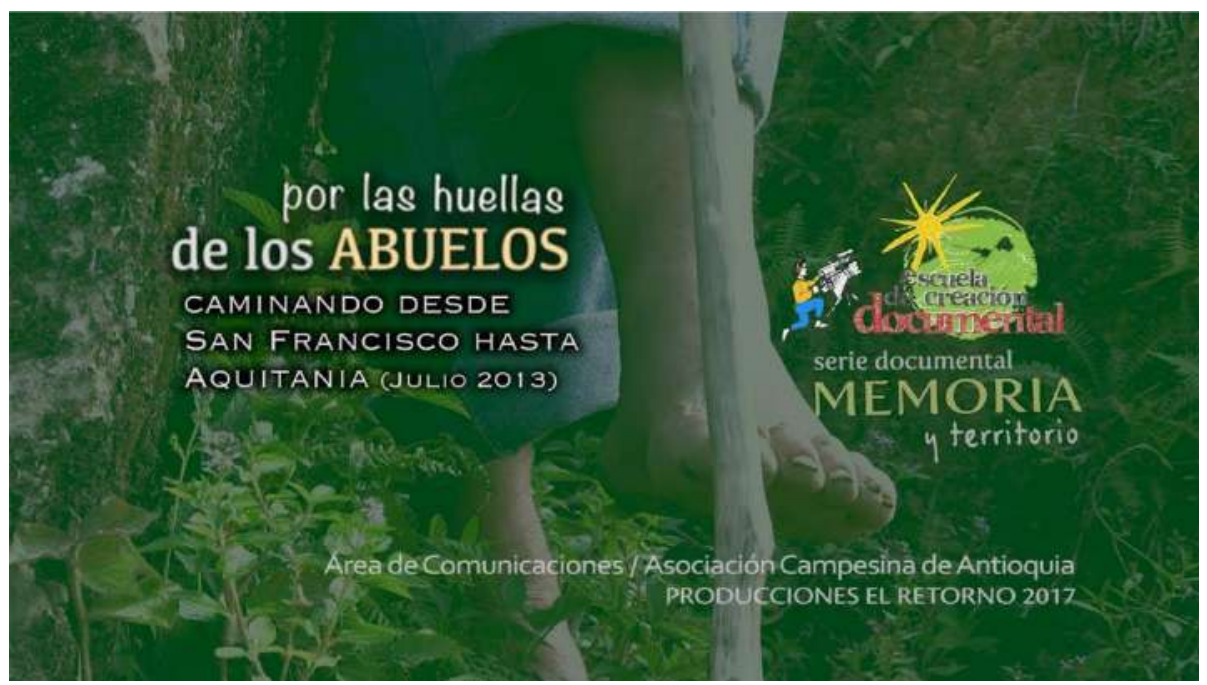

Figura 5. Presentación del documental Por las huellas de los abuelo de la serie Memoria y Territorio. Asociación Campesina de Antioquia, ACA.

Fuente: Documental Campesino-Producciones El Retorno (2016).

Estos agentes, que a menudo son endógenos (aunque podrían ser foráneos y haber construido vínculos fuertes con las comunidades), tienen conocimientos sobre técnicas de realización audiovisual de manera previa o los van adquiriendo durante el proceso para ponerlos al servicio de la comunidad. Estos conocimientos los relacionamos con la influencia educativa porque, en relación con lo que propone Mesa (2004), se han planteado como procesos intencionados y organizados. Es el agente educativo el que acompaña a los participantes en el proceso de construcción de significados.

La tercera dimensión se identifica en los aprendizajes que se comparten o se heredan durante el proceso, lo que se denomina cesión y traspaso progresivo de la responsabilidad (Mesa, 1998). Se trata, entonces, de que la comunidad ponga en juego sus motivaciones por pertenecer a los colectivos y procesos. Al mismo tiempo, se activa el interés por aprender y asumir responsabilidades que se heredan, lo que da cabida a transformaciones que se pueden mantener en el tiempo. La Escuela de Creación Documental y los semilleros creativos de la ACA son ejemplos de la consolidación y renovación de las obras expresivas audiovisuales comunitarias como estrategias comunicativas y recreativas con potencial de transformación social en el tiempo (figura 6).

\section{Metodología}

El diseño metodológico que posibilitó identificar, entre los años 2016 y 2018, dieciocho experiencias de audiovisual comunitario en Colombia y estudiar en profun- 
didad dos de ellas, tuvo un enfoque cualitativo de carácter etnográfico. Se trabajó con tres formas de la etnografía: la clásica, apoyada en observación profunda, descripción densa (Geertz, 2003) y comprensión de cada proceso (Martínez, 2005); la virtual (Hine, 2004), que facilitó la ubicación de las experiencias que tienen páginas en internet o perfiles en redes sociales, a través de las cuales se les pudo hacer un seguimiento en el tiempo; y la audiovisual (Robles, 2012), que fue el soporte para analizar algunas obras.

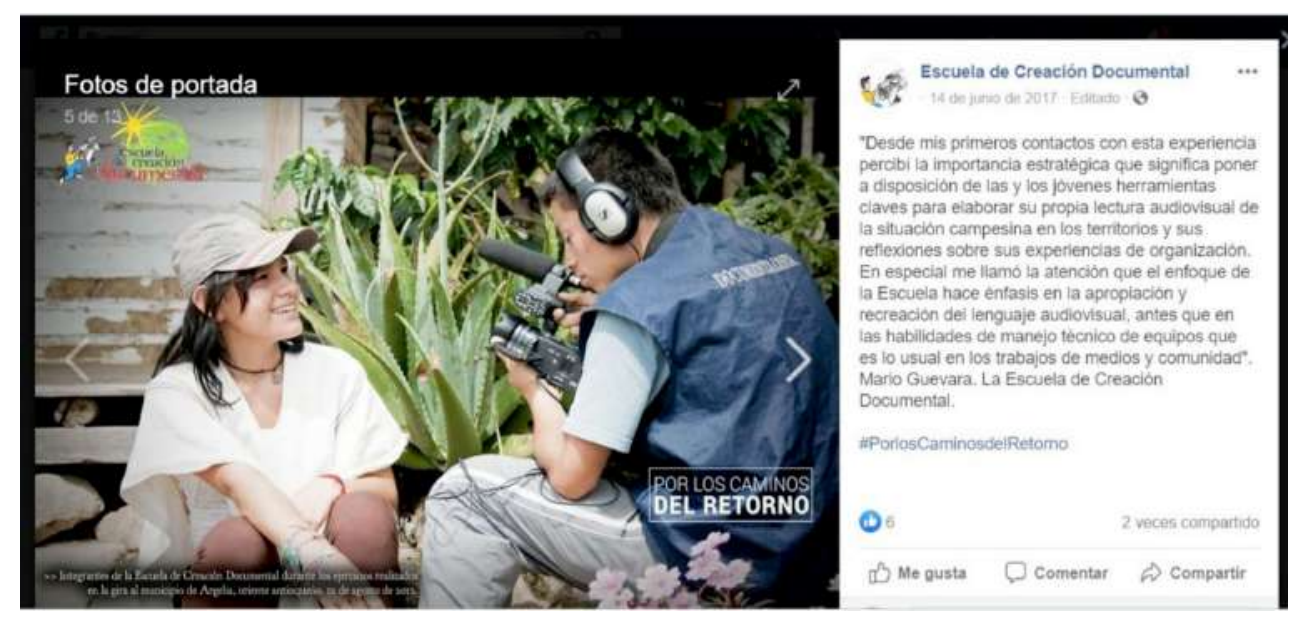

Figura 6. Los jóvenes de la Escuela de Creación Documental de la ACA son líderes de las obras que desarrollan

Fuente: Escuela de Creación Documental de la ACA (2017).

De las experiencias identificadas, se eligió ahondar en el estudio de la muestra de cine y video indígena Daupará por ser un espacio de encuentro, diálogo y aprendizaje colectivo; y de la Escuela de Creación Documental de la Asociación Campesina de Antioquia (ACA) por desarrollar obras con jóvenes campesinos, por la cantidad y buena factura técnica de sus procesos audiovisuales comunitarios, así como por su permanencia y constancia en el tiempo.

Además de visitar el Semillero Creativo de la ACA en el municipio de San Francisco (Antioquia) y de asistir al Daupará realizado en Bogotá en dos años diferentes (2015 y 2017), también se visitó a los organizadores del Festival Internacional de Cine Comunitario Afro "Kunta Kinte" en Medellín, se pudo hablar con el Colectivo Ángeles de Calle en Cartagena y se visitó al Colectivo de Comunicaciones Kuchá Suto en San Basilio de Palenque. En la ciudad de Cali se entrevistaron a representantes de cinco experiencias: Tikal Producciones, Cine pa’l Barrio, Cine Convivo, Nasa Luuçx Comunicaciones y, como artesano audiovisual independiente, se visitó a Víctor Alfonso González Urrutia en Villapaz, Jamundí, Valle del Cauca. En total, entre conversaciones 
cara a cara, vía telefónica o a través de internet, se entrevistaron veintisiete realiza dores audiovisuales.

El análisis de la muestra de seis documentales de la Escuela de Creación Documental de la ACA: Cuando voy a la escuela (2012), Represando el porvenir (2014), Sembrando dignidad (2015), Pa' mí es historia (2015), Si uno piensa, no se deja (2016), Por las huellas de los abuelos (2017), se realizó observando los filmes, cruzando los hechos documentados en estos con fuentes periodísticas y entrevistando a sus realizadores. Para sistematizar el análisis, se diseñó una ficha de registro basada en los elementos y fases desarrollados por Robles (2012) y los planteamientos de García (2011).

\section{Resultados}

\section{Las OEAC como alternativa lúdico-creativa o mediación semiótica}

Desde la perspectiva de la comunicación basada en las mediaciones, "la comunicación no es reducible ni homologable a la trasmisión ni medición de información, porque no cabe en el esquema de —emisor/mensaje/receptor-" (Martín-Barbero, 1991, p. 223). Por consiguiente, el concepto de mediación es un aspecto clave a entender en este apartado. Para Martín-Barbero las mediaciones que dan sentido al acto comunicativo tienen lugar en los usos, las relaciones y los vínculos que se construyen en los procesos de comunicación.

Por otra parte, Mesa (2004) considera los lenguajes lúdico-creativos como mediaciones por su carácter de herramienta semiótica o de lenguaje. No interesan como actividad práctica o técnica, sino por su potencial para influir como herramientas semióticas en las construcciones de la actividad interna. En este sentido, afirma:

La formulación de lenguajes lúdico-creativos, surge de interpretar los postulados sobre el papel de las mediaciones semióticas en la estructuración de las funciones psicológicas superiores; esto significa que los sistemas de pensamiento son el producto de la interiorización de procesos de mediación desarrollados por y en las culturas... (p. 12)

Planteamos entonces que las OEAC, además de funcionar socialmente como mediaciones en el sentido desarrollado por Martín-Barbero (1991), están conformadas por mediaciones semióticas o lenguajes lúdico-creativos porque

sirven como instrumentos de mediación y junto al lenguaje intervienen en las situaciones pedagógicas de la actividad recreativa, sirven de elementos transicionales para construir cambios significativos en la actividad interna de las personas (imaginación creadora, afectividad, socialización, cognición, entre otras). (Mesa, 2004, p. 12) 
En experiencias como la de la Escuela de Creación Documental de la ACA, cuyo centro de acción es el Oriente antioqueño, o en la Escuela Audiovisual Infantil de Belén de los Andaquíes en el Putumayo (figura 7), queda claro el poder transformador de las mediaciones audiovisuales. Se trata de zonas que han sido fuertemente golpeadas por la violencia histórica colombiana, donde volver a soñar y poder crear ha sido una oportunidad invaluable para las personas que han hecho parte de los procesos audiovisuales.

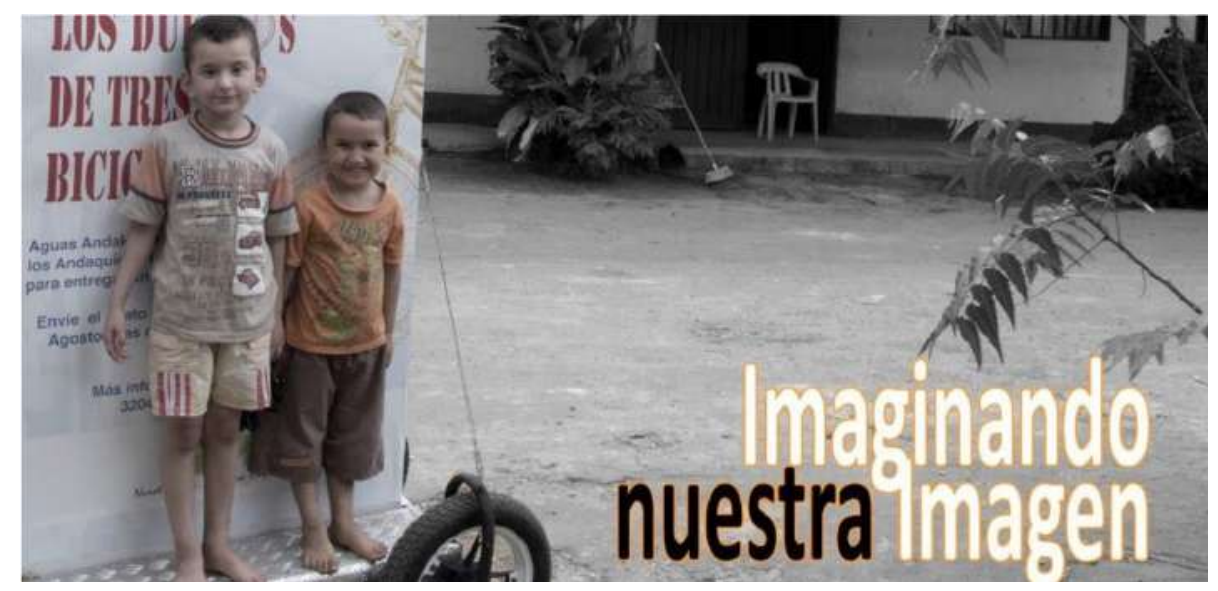

Figura 7. Escuela Audiovisual Infantil de Belén de los Andaquíes

Fuente: Escuela Audiovisual Infantil (2012).

En estos casos, las mediaciones audiovisuales, en tanto juego creativo de sonidos e imágenes, han sido un camino lúdico para narrar las propias historias, visibilizarlas sin amarillismos ni lamentaciones (figura 8). De esta manera, se resignifican vivencias y se reflexiona sobre ellas para procesarlas, activar la memoria colectiva, reconocer el pasado, el presente y soñar con un futuro dentro de los propios territorios.

Las obras expresivas audiovisuales comunitarias de las que hablamos en este estudio están arraigadas en un proceso comunitario complejo y de, maneras diversas, se hacen cargo de tramitar las experiencias y eventos críticos de sus comunidades: el desplazamiento forzado, la implicaciones de la vida urbana y universitaria para jóvenes indígenas, la diversidad sexual y de género, la memoria colectiva, el posconflicto, las festividades y formas de encuentro comunitarios, las subjetividades de habitantes contemporáneos, la riqueza medioambiental de las regiones y las amenazas a las que se enfrenta, las prácticas culturales tradicionales y emergentes, la ausencia del Estado y sus deudas históricas con las comunidades, las transformaciones en la vida cotidiana de las comunidades campesinas e indígenas, entre otras. (Gómez, González y Valencia-Calero, 2020, pp. 179-180) 


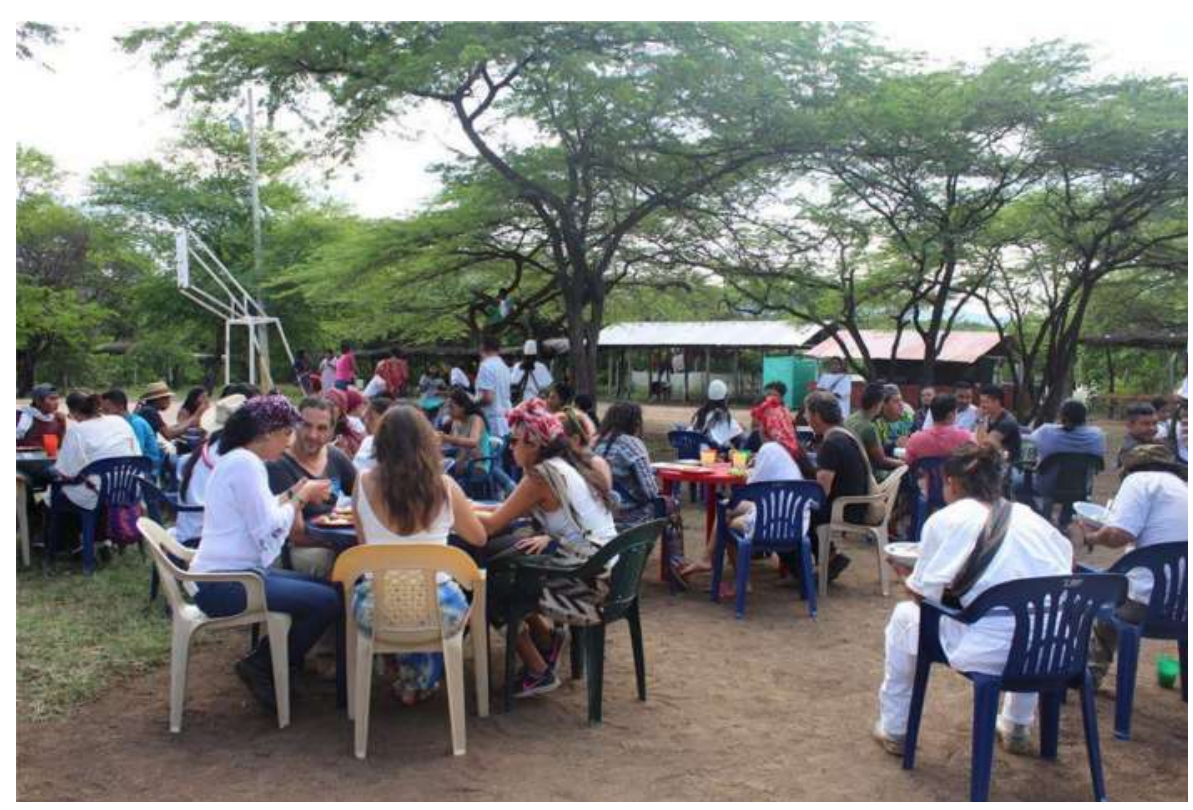

Figura 8. Muestra de cine y video indígena Daupará

Fuente: Daupará-Muestra de Cine y Video Indígena en Colombia (2018).

\section{Creación o fortalecimiento de vínculos sociales}

El vínculo social, tejer lazos entre las comunidades entre estas y el exterior, es una intención fundamental de las OEAC. Sentirse acompañado o identificado con otros crea o transforma sentidos del ser y del hacer. Puede cambiar la forma de apreciar situaciones y de afrontar problemas, quizá de una manera menos solitaria y desencantada. Un ejemplo de algo así lo presenta Villanueva (2015) al contar una anécdota en la proyección de un filme llamado

El oro o la vida (Álvaro Revenga, 2011), que expone el tema de la minería a cielo abierto que se realiza en Centroamérica, circuitos de exhibición, tanto en Guatemala como en Colombia, en Daupará, en territorio wayuu y en Tierradentro, el público se identificó con los hermanos indígenas en esos países (...) Recuerdo que después de la proyección de esta misma película, durante una asamblea con más de 300 personas en el Resguardo de San Miguel de Turminá, en Tierradentro, una mayora, de mínimo 80 años, me llamó -se veía en su rostro la alegría-y me dijo: 'estoy muy contenta, porque yo pensaba éramos poquitos, yo casi como no salgo, pero viendo este video veo que somos muchos, iqué no estamos luchando solos! (pp. 210-211)

Para identificar, describir y analizar los vínculos presentes en una obra expresiva audiovisual comunitaria se le concibe como un texto a leer en cada una de sus dimensiones: forma, contenido, personajes, testimonios, contextos, realizadores, créditos, 
agradecimientos, espacios de proyección, reacciones de la comunidad, trascendencia en el tiempo. Es fundamental enfatizar que la comunicación, más allá de unos medios tecnológicos, aporta posibilidades de vinculación social y de transformación de sentidos (figura 9). En relación con el primer elemento, se considera que los "vínculos están hechos, básicamente, de trabajo humano, es decir, los vínculos son prácticas y acciones realizadas por personas" (Almendra et al., 2011, p. 91) para relacionarse con otros individuos, organizaciones, redes e, incluso, con la historia y la memoria. Con respecto a la resignificación, se podría plantear aquí que existe en el lenguaje audiovisual y en las OEAC elementos de poetización (Gómez, 2016), lo que significa que se crean y transforman sentidos y sentimientos respecto a determinadas realidades y vivencias.

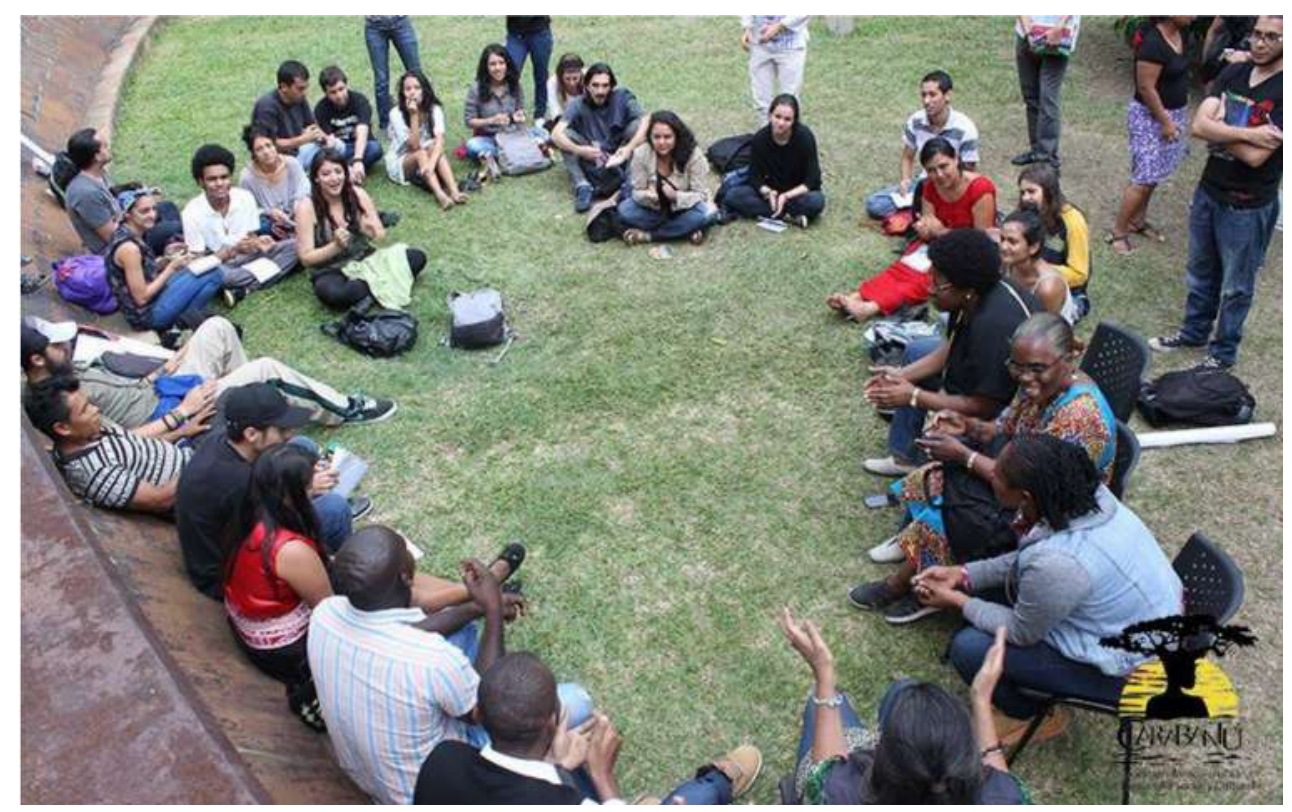

Figura 9. Ficca Kunta Kinte, encuentro de diálogo en torno a las lenguas nativas Fuente: Kunta Kinte Carabantú (2016).

Las OEAC abren caminos para poetizar la vida cuando se graban momentos y personajes que se pueden ver y volver a ver sin límite de veces; cuando se conoce la historia, se construye memoria o cuando se juega a recrear realidades o a crear ficciones con imágenes y sonidos (figura 10). En la posibilidad de soñar y de jugar se hallan formas de resistencia comunitaria, porque "el sueño es tan necesario para los sujetos políticos, transformadores del mundo y no adaptables a él, como fundamental es para el trabajador — permítaseme la repetición — proyectar en su cerebro lo que va a hacer, antes de la ejecución" (Freire, s.f., p. 117). 


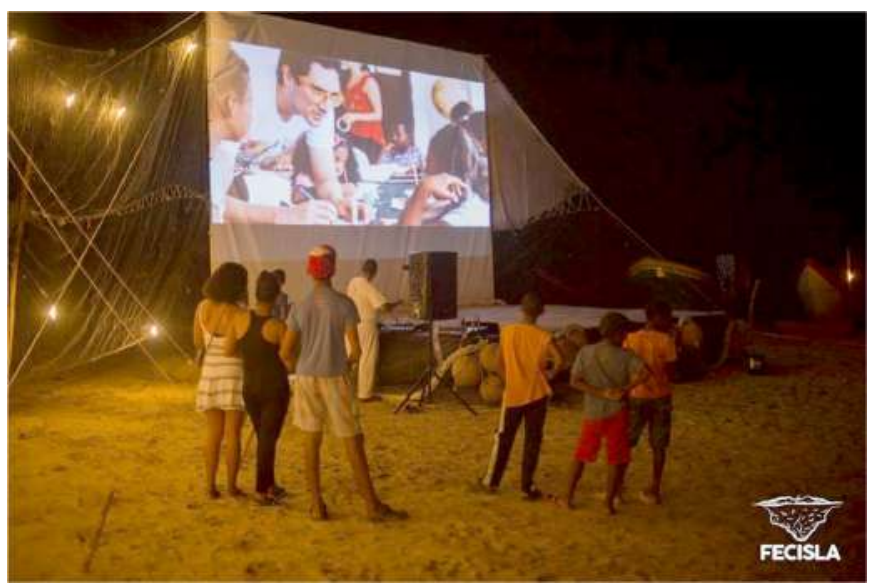

Figura 10. El Festival Internacional Cine en Isla desarrolla procesos expresivos, sociales y pedagógicos con la comunidad de Isla Fuerte, Departamento de Bolívar.

Fuente: Fecisla (2018).

Las OEAC realizadas por niños, niñas y jóvenes se han convertido en retos para representar con símbolos propios lo que se es como persona, como comunidad o lo que las palabras no pueden comunicar. La negociación de significados pasa por lo más simple — como un niño pintando sus sueños en y luego filmándolos en la Escuela Audiovisual Infantil de Belén de los Andaquíes (figura 11)— hasta por lo más complejo cuando se trata de imágenes indígenas, cargadas de significados espirituales. En ambos ejemplos las realidades de cada contexto se recrean desde referentes emocionales propios (Zamorano, 2009) y esto permite tramitar recuerdos, miedos, ausencias, duelos, extrañamientos, así como alegrías, deseos y otros tantos sentimientos.

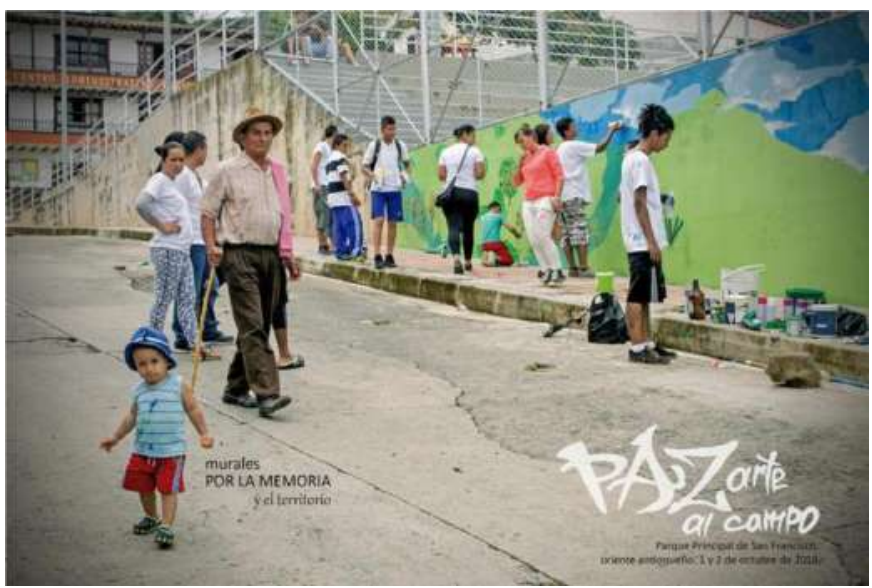

Figura 11. la comunidad pinta un mural por la memoria y el territorio.

Fuente: Producciones El Retorno (2017). 
La posibilidad de registrar la propia historia (individual o colectiva) es una de las posibilidades que ofrecen las OEAC. Las vivencias y hechos sociales, una vez narrados con imágenes en movimiento, se reactivan: "aunque la historia es una experiencia distante, su apropiación a través de 'la memoria de nuestros antepasados' permite movilizarla como algo compartido y, por lo tanto, darle un sentido político" (Zamorano, 2009). En su estudio sobre las producciones audiovisuales indígenas en Bolivia, Zamorano expone cómo la realización de un video o de una película puede ser, en sí misma, intervenir la realidad. El proceso de visibilización y reconocimiento de la historia o de las problemáticas sociales a través de un audiovisual abre espacios de reflexión y diálogo en las comunidades que podría desencadenar en acciones concretas fuera de las pantallas.

\section{Discusión y conclusiones}

Como resultado de este estudio, cuya base es el análisis de experiencias, nos ha quedado claro que en Colombia muchas comunidades se están expresando, están interviniendo sus propias realidades y se están proyectando, hacia adentro y hacia afuera, a través de obras expresivas audiovisuales comunitarias. Se tiene claro que los audiovisuales realizados con y para las comunidades tienen diferentes maneras de nombrarse: comunitarios, alternativos, populares, entre otros. Sin embargo, lo que se señala en este artículo es que las OEAC no son películas, sino procesos activados, dinamizados o acompañados por mediaciones audiovisuales.

Estos procesos cuentan con un componente humano endógeno considerable, aunque, a menudo (con frecuencia al inicio de los procesos), han tenido el apoyo de actores externos (comunicadores, cineastas, antropólogos o realizadores empíricos con trayectoria) que se han vinculado a las comunidades de manera respetuosa, como acompañantes, y han aportado conocimientos e ideas sin determinar los propósitos y el desarrollo de las obras.

Los grupos, colectivos y organizaciones que han asumido la realización de obras expresivas audiovisuales comunitarias como forma de expresión, resistencia, negociación de sentidos y creación de proyectos comunes, también han hallado en estos procesos maneras colectivas de construcción de conocimientos (Gómez, González y Valencia-Calero, 2020). En estos procesos se hace prioritario respetar los saberes, sentimientos, formas de pensamiento y aportes de los sujetos participantes. Las OEAC son localizadas, se gestan en contextos con condiciones específicas que las determinan, y esto se debe tener presente todo el tiempo. Los tiempos de cada obra son los de las comunidades, lo que implica ser flexibles, muy recursivos y estar abiertos a mayores y nuevos aprendizajes; esto es posible porque no hacen parte de circuitos industriales de cine o video. Las transformaciones sociales estructurales y la resignificación de vivencias toman tiempo. 
Estas obras tienen propósitos definidos con las comunidades, asumen posturas frente a las propias realidades y lo hacen desde sus referentes culturales, simbólicos, emocionales y políticos. Su componente educomunicativo pone en primer lugar el diálogo, la deliberación y la apertura a diferentes formas de pensamiento. Reconocen el conflicto y también la esperanza. Potencian la capacidad de soñar de los sujetos. Son formativas y, con frecuencia, crean semilleros creativos o escuelas que fomentan la construcción de conocimientos y la proyección de nuevas OEAC (figura 12).

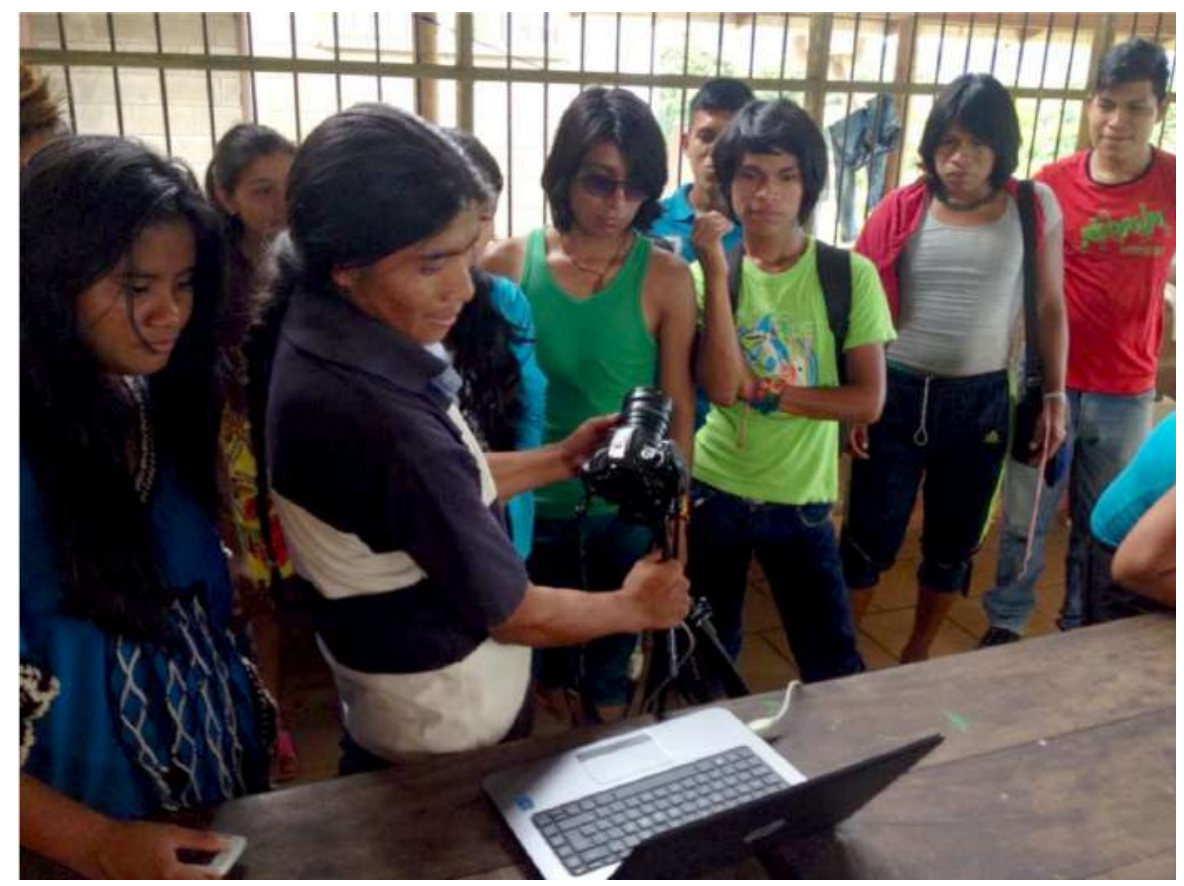

Figura 12. Taller de animación con el comunicador ecuatoriano Segundo Fuerez durante una las actividades académicas de la muestra de cine y video indígena Daupará

Fuente: Daupará-Muestra de Cine y Video Indígena en Colombia (2016).

Finalmente, a partir de este estudio, se considera que las obras expresivas audiovisuales comunitarias abren posibilidades de transformación social, porque reconocen los aspectos sociohistóricos de las comunidades, fortalecen la identidad colectiva y hacen posible una fluida (viva) relación entre sujetos y contextos. Son una alternativa para tramitar acontecimientos del pasado, comprender el presente y realizar proyecciones a futuro. Los componentes educomunicativos y recreativos marcan diferencias respecto a otros enfoques de los audiovisuales en ámbitos comunitarios. En medio de los procesos hay elementos de aprendizaje que brindan nuevas maneras de leer el mundo, de construir vínculos con los otros y de narrar las propias vivencias. Desde lo pedagógico, 
las OEAC devienen educativas, en tanto crean condiciones para que los sujetos y las comunidades se repiensen y reconfiguren sus vínculos internos y externos. El estudio nos mostró que con la realización de una obra expresiva audiovisual comunitaria, algo ocurre, algo se mueve y cambia; se abren nuevas brechas de diálogo, más y mejores conflictos, eclosionan preguntas y perspectivas inesperadas que muchas veces desafían las miradas románticas y poco complejas de la vida comunitaria. Participar en el proceso de producción de una OEAC involucra un componente ontológico esencial al conseguir que los participantes experimenten formas diversas de transformación. (Gómez, González y Valencia-Calero, 2020, p. 180)

\section{Referencias}

Acaso, M. y Ávila, N. (2011). Una profesión reconocida en contextos de salud: la educación artística. Arte, Individuo y Sociedad, 23, 19-27.

Aguilera, C. y Polanco, G. (2011). Luchas de representación: Prácticas, procesos y sentidos audiovisuales colectivos en el suroccidente colombiano. Programa Editorial Universidad del Valle.

Almendra, V., Giraldo, D., Gómez, R., González, J., Grillo, O., Henao, H., Rueda, R., Ulcué, G. y Unás, V. (2011). Tierra y silicio: Cómo la palabra y la acción política de pueblos indígenas cultivan entornos digitales. Programa Editorial Universidad del Valle.

Anisur, M. y Fals, O. (2013). Situación actual y perspectivas de la Investigación- Acción Participativa en el mundo. En N. Herrera Farfán. Ciencia, compromiso social y cambio social. Orlando Fals Borda Antología (pp. 253-264). El Colectivo.

Barbas-Coslado, Á. (2012). Educomunicación: desarrollo, enfoques y desafíos en un mundo interconectado. Foro de Educación, (14), 157-175.

Besnard, P. (1988). La animación sociocultural. Oikos-tau.

Boal, A. (2006). The aestetics of the oppressed. Routledge.

Colectivo de comunicaciones Kuchá Suto. (2016, 25 de junio). Sin título [Imagen adjunta] [Actualización de estado]. Facebook. Consultado el 15 de mayo de 2017. https://www. facebook.com/photo.php?fbid=1196215163878322Eset=pb.100004695487264.2207520000.1567309845.Etype=3Etheater

Couldry, N., Rodríguez, G. y Bolin, G. (2018). Media, Communication, and the Struggle for Social Progress. Global Media and Communication, 14(2), 173-191.

Daupará-Muestra de Cine y Video Indígena en Colombia. (2016, 16 de noviembre). Taller de Animación [Imagen adjunta] [Actualización de estado]. Facebook. Consultado el 15 de mayo de 2017. https://www.facebook.com/dauparacine/photos/a.10152841033701285/10154569 388851285/?type $=3 \mathcal{E}$ theater

Daupará-Muestra de Cine y Video Indígena en Colombia. (2018, 3 de octubre) Mayabangloma [Imagen adjunta] [Actualización de estado]. Facebook. Consultado el 12 de diciembre de 2018. https://www.facebook.com/photo.php?fbid=2255167767830059Eset $=$ a. 225516253 1163916 Etype $=3$ Etheater 
De Oliveira, I. (2008). El derecho a la pantalla: de la educación en medios a la educomunicación en Brasil. Comunicar. Revista Científica de Comunicación y Educación / The right to screens: from media education to educommunication in Brazil, XV(30), 87-92.

Documental Campesino-Producciones El Retorno. (2016, 6 de marzo). Si uno piensa, no se deja [Imagen adjunta] [Actualización de estado]. Facebook. Consultado el 4 abril de 2017 . https:// www.facebook.com/photo.php?fbid=1330983050252598Eset = pb. 100000227472746 . 2207520000..Etype $=3$

Escuela Audiovisual Infantil. (2012, 9 de septiembre). Imaginando nuestra imagen [Imagen adjunta] [Actualización de estado]. Facebook. Consultado el 15 de mayo de 2017. https://www.facebook. com/eainfantil/photos/a.381807725173638/460862130601530/?type=3Etheater

Escuela audiovisual infantil. (2016, 1 de abril). ¿Dónde está la tensión? [Imagen adjunta] [Actualización de estado]. Facebook. Consultado el 15 de mayo de 2017. https://www.facebook.com/ eainfantil/photos/a.200735049947574/1113103878710682/?type=3Etheater

Escuela de Creación Documental de la ACA. (2017, 14 de junio) Por los caminos del retorno [Imagen adjunta] [Actualización de estado]. Facebook. Consultado el 15 de agosto 2017. https://www. facebook.com/escuela.documental/photos/a.1726598730906728/1959375217629077/?type $=3$ Etheater

Escuela de Creación Documental de la ACA (dirección). (2012). Cuando voy a la escuela/Un documental colectivo [Película]. Producciones El Retorno.

Escuela de Creación Documental de la ACA (dirección). (2014). Represando el porvenir [Película]. Producciones El Retorno.

Escuela de Creación Documental de la ACA (dirección). (2015). Pa’ mí es historia [Película]. Producciones El Retorno.

Escuela de Creación Documental de la ACA (dirección). (2015). Sembrando dignidad [Película]. Asociación Campesina de Antioquia.

Escuela de Creación Documental de la ACA (dirección). (2016). Si uno piensa, no se deja [Película]. Producciones El Retorno.

Escuela de Creación Documental de la ACA (Dirección). (2017). Por las huellas de los abuelos [Película]. Producciones El Retorno.

Espinosa, J. (2012). El video participativo: herramienta para la transformación social en procesos pedagógicos, sociales y políticos. Diseño de propuestas para dos casos en la península ibérica. Revista Nexus, 1(12), 64-75.

Festival Internacional de Cine en la Isla. (2018, 19 de enero). Sin título [Imagen adjunta] [Actualización de estado]. Facebook. Consultado 24 de febrero de 2018. https://www.facebook. com/fecisla/photos/a.1566680826748059/1568517779897697/?type=3Etheater

Fals, O. (2013). Action Research in the Convergence of Disciplines. International Journal of Action Research, 155-167.

Freire, P. (1975). Acción cultural para la libertad. Tierra Nueva. https://www.academia.edu/39367432/ Freire_Paulo__Acci\%C3\%B3n_Cultural_para_la_Libertad 
Freire, P. (s.f.). Pedagogía de la esperanza. Un reencuentro con la pedagogía del oprimido. Siglo XXI Editores. https://cronicon.net/paginas/Documentos/paq2/No.11.pdf

García, M. (2011). El vídeo como herramienta de investigación. Una propuesta metodológica para la formación de profesionales en Comunicación. Revista el CES Felipe II(13). http://www. cesfelipesegundo.com/revista/articulos2011/Monica\%20Garcia.pdf

Geertz, C. (2003). La interpretación de las culturas. Gedisa.

Gómez, R. (2016). Sobre los Procesos de Poetización en Facebook. En R. Gómez., J. González., R.Rueda., y V. Valencia (Eds.) Facebook como Obra Mundana: Poetizar la Vida y Recrear Vínculos Personales (pp. 287-295). Programa Editorial Universidad del Valle.

Gómez, R., González, J. y Valencia-Calero, V. (2016). Proyecto de investigación. Elementos de educación popular y recreación presentes en trabajos audiovisuales realizados por organizaciones o comunidades como parte de procesos de movilización, participación y creación o fortalecimiento de vínculos sociales. Universidad del Valle.

Gómez, R., González, J. y Valencia-Calero, V. (2020). Comunidades en video: nos ven, los vemos y nos movemos. Programa Editorial de la Universidad del Valle.

Goyeneche-Gómez, E. (2012). Las relaciones entre cine, cultura e historia una perspectiva de investigación audiovisual. Palabra Clave, 3(15), 387-414.

Gumucio-Dragon, A. (2011). Comunicación para el cambio social: clave del desarrollo participativo. Signo y Pensamiento, XXX(58), 26-39.

Hine, C. (2004). Etnografía virtual. Editorial UOC.

Hleap, J. (2013). Diez lecciones aprendidas en cuatro décadas de educomunicacion en América Latina. Nexus, (14), 184-201.

Huergo, J. (2008). La relevancia formativa de las pantallas / The formative relevance of screens. Comunicar. Revista Científica de Comunicación y Educación, XV(30).

Huergo, J. (10 de 08 de 2015). Comunicación/Educación: itinerarios transversales. https://www.caja-pdf. es/2015/08/10/comunicaci-n-huergo/comunicaci-n-huergo.pdf

Kunta Kinte Carabantú. (2016, 7 de marzo). Sin título [Imagen adjunta] [Actualización de estado]. Facebook. Consultado el 15 de mayo de 2017. https://www.facebook.com/photo.php?fbid= 194485837589189 Eset $=$ a. 194485667589206 Etype $=3$ Etheater

Martín-Barbero, J. (1991). De los medios a las mediaciones Comunicación, cultura y hegemonía. Ediciones G. Gili, S.A. de C.V.

Martínez, M. (2005). El método etnográfico de investigación. https://www.uis.edu.co/ webUIS/es/investigacionExtension/comiteEtica/normatividad/documentos/ normatividadInvestigacionenSeresHumanos/13_Investigacionetnografica.pdf

Mesa, G. (1998, 3 de noviembre). La recreación como Proceso Educativo. [ponencia]. V Congreso Nacional de Recreación, Manizales, Caldas, Colombia. http://www.redcreacion.org/documentos/ congreso5/GMesa.htm 
Mesa, G. (2004). La recreación "dirigida": ¿Mediación Semiótica y Práctica Pedagógica? -Una pregunta para el debate-. Universidad del Valle.

Monenegro, E. (2019, 7 de febrero). Sin título [Imagen adjunta] [Actualización de estado]. Facebook. Consultado el 4 de abril de 2019. https:/www.facebook.com/photo.php?fbid=10217879210 987216Eset=pb.1091695646.-2207520000.1567308911.Etype=3Etheater

Narváez-Montoya, A. (2019). Comunicación educativa, educomunicación y educación mediática: una propuesta de investigación y formación desde un enfoque culturalista. Palabra Clave, 22(3), 1-30.

Producciones El Retorno. (2017, 19 de mayo). Sin título [Imagen adjunta] [Actualización de estado]. Facebook. Consultado el 18 de julio de 2019. https://www.facebook.com/elretornocolombia/ photos/a.1806603196323341/1806616459655348/?type=3Etheater

Restrepo, P.; Valencia, J. (2016). Political activism before the premiere: indigenous audiovisual production, knowledge otherwise and gender complementarity inthe Wiwa film Ushui. Critical Arts, 754-769. https://doi.org/10.1080/02560046.2016.1263675

Robles, J. (2012). El lugar de la Antropología audiovisual: metodología participativa y espacios profesionales. Íconos. Revista de Ciencias Sociales, (44), 147-162.

Villanueva, R. (2015). Audiencias Indígenas. En P. Mora (Ed.), Poéticas de la resistencia. El video indígena en Colombia (pp. 193-212). Cinemateca Distrital; Idartes.

Zamorano, G. (2009). "Intervenir en la realidad": usos políticos del video indígena en Bolivia. Revista Colombiana de Antropología. http://www.redalyc.org/articulo.oa?id=105012402001 